\title{
Evidence to support the use of vildagliptin monotherapy in the treatment of type 2 diabetes mellitus
}

This article was published in the following Dove Press journal:

Vascular Health and Risk Management

17 May 2012

Number of times this article has been viewed

\author{
Sylvie Dejager' \\ Anja Schweizer ${ }^{2}$ \\ James E Foley ${ }^{3}$ \\ 'Novartis Pharma SAS, Rueil \\ Malmaison, France; ${ }^{2}$ Novartis Pharma \\ AG, Basel, Switzerland; ${ }^{3}$ Novartis \\ Pharmaceuticals Corporation, East \\ Hanover, NJ, USA
}

\begin{abstract}
The efficacy and safety of the dipeptidyl peptidase-4 inhibitor, vildagliptin, as monotherapy have been widely confirmed in a large body of clinical studies of up to 2 years' duration in various populations with type 2 diabetes mellitus. This paper reviews the data supporting the use of vildagliptin in monotherapy. Consideration based on baseline glycated hemoglobin levels and age is given to patient segments where metformin is not appropriate. In addition, although prediabetes is not an indication, this manuscript briefly reviews some of the existing data showing that the mechanisms at work in diabetic populations are active in patients currently classified as prediabetic, with impaired glucose tolerance or impaired fasting glucose. Finally, the rationale for vildagliptin dosing frequency in monotherapy is discussed. In summary, this review aims to define where in community practice the use of vildagliptin as monotherapy is most desirable, focusing on segments of the population with type 2 diabetes mellitus that might receive the greatest benefit from vildagliptin in the management of their disease.
\end{abstract}

Keywords: vildagliptin, type 2 diabetes, dipeptidyl peptidase-4 inhibitors, monotherapy, elderly

\section{Introduction}

Vildagliptin is a potent and selective dipeptidyl peptidase-4 inhibitor (DPP-4) that blocks dipeptidyl peptidase-4 inactivation of glucagon-like peptide-1 (GLP-1) and glucosedependent insulinotropic polypeptide (GIP). ${ }^{1}$ Vildagliptin has been extensively studied in multiple clinical studies, including various populations with type 2 diabetes mellitus (T2DM). ${ }^{2}$ The drug has demonstrated efficacy when given as monotherapy or in combination with other antidiabetic drugs or insulin..$^{2-4}$ Vildagliptin is well tolerated and has a low risk of hypoglycemia and weight gain. Its efficacy when added to metformin ${ }^{5}$ as well as its safety (overall ${ }^{6}$ but also with respect to cardiovascular and cerebrovascular events ${ }^{7}$ and adverse events of special interest ${ }^{8}$ ) has been thoroughly reviewed elsewhere, including in special populations such as the elderly. ${ }^{9,10}$ Several recent reviews have also focused on a number of the drug's additional key features, including its mechanism of action, ${ }^{11}$ its weight neutrality, ${ }^{12}$ and its benefit in terms of hypoglycemia. ${ }^{13}$ Additionally, the overall efficacy and safety of vildagliptin were assessed in a recent meta-analysis. ${ }^{14}$

Numerous clinical studies of vildagliptin monotherapy have been published, although these papers do not provide any guidance as to how vildagliptin might be used as monotherapy in clinical practice. Therefore, we deemed it important to try to define how the drug might be used most effectively in monotherapy, ie, which segments of the diabetic population would benefit most from vildagliptin monotherapy.
Correspondence: Sylvie Dejager Novartis Pharma SAS, 2 et 4 rue Lionel Terray, 92506 Rueil Malmaison, France Tel +33I 55476339

Fax +33I 55476593

Email sylvie.dejager@novartis.com 
Currently, most T2DM patients begin and then continue gold standard treatment of metformin. ${ }^{15}$ However, a small percentage of patients cannot tolerate metformin due to gastrointestinal side effects, such as diarrhea and nausea, ${ }^{16}$ and metformin is contraindicated for individuals with congestive heart failure, renal disease, or acute or chronic acidosis. For example, in a recent US cohort from Kaiser Permanente, $17 \%$ of patients who started metformin monotherapy discontinued before 6 months. ${ }^{17}$ In some countries (predominantly in Asia), the alpha-glucosidase inhibitors (eg, acarbose, migital) are frequently used instead of metformin as first-line therapies. The use of alphaglucosidase inhibitors is limited by its dosing requirements (taken three times daily before meals), by its gastrointestinal symptoms (arising from fermentation of undigested carbohydrates by colonic bacteria), and by the fact that both its efficacy and its gastrointestinal side effects are influenced by diet (with an advantage when rice is the major source of carbohydrate in the diet)..$^{18}$

Alternatives for patients who cannot take metformin include the thiazolidinediones and the sulfonylureas. However, the use of thiazolidinediones is quite limited at present. Even pioglitazone (the only available glitazone in Europe) might not remain a common alternative over the years to come because of uncertainties about its safety, given that long-term use has been associated with elevated rates of bone fracture ${ }^{19}$ and bladder cancer. ${ }^{20,21}$ In most countries, the most common first-line alternatives to metformin are the sulfonylureas, eg, gliclazide, glimepiride, glibenclamide, and glipizide. The major limitations of sulfonylureas are an increased risk of hypoglycemia and weight gain. ${ }^{22}$ These limitations are most evident when sulfonylureas are used in patients with lower baseline glycosylated hemoglobin $\left(\mathrm{HbA}_{1 \mathrm{c}}\right.$ ) levels (in particular $\left.\leq 8 \%\right),{ }^{23}$ and in elderly patients, who are at risk of more frequent and severe hypoglycemia and for whom the potential consequences of hypoglycemia are more dangerous. ${ }^{24}$ Thus, for those individuals, sulfonylureas may not be optimal first-line therapy and vildagliptin could represent an interesting option.

This paper examines the data for vildagliptin in these particular segments of the T2DM population. In addition, although prediabetes is currently not an accepted indication in most countries (except, eg, voglibose in Japan or acarbose in China), this paper will also review the data with vildagliptin in individuals classified as having prediabetes with impaired glucose tolerance or impaired fasting glucose in whom the mechanisms are already operative. ${ }^{11}$ An overview of all studies discussed in this paper is presented in Table 1.

\section{Overview and patients with mild hyperglycemia}

We will first briefly review the main data in the broad monotherapy population and then focus on the patient segments of particular interest. The overall efficacy of vildagliptin in monotherapy has been well demonstrated in several pivotal studies. ${ }^{25-34}$ All these studies were conducted in drug-naive patients with T2DM independent of intolerance or contraindications to metformin. These monotherapy studies provide evidence that treatment with vildagliptin results in consistent and clinically meaningful reductions from baseline in $\mathrm{HbA}_{1 \mathrm{c}}$ of approximately $-1 \%$, without weight gain and with minimal hypoglycemia.

In an early trial, conducted in 780 patients randomized to vildagliptin $50 \mathrm{mg}$ twice daily or metformin $2 \mathrm{~g}$ daily, robust $\mathrm{HbA}_{1 \mathrm{c}}$ reductions from a baseline of $8.7 \%$ were attained at one year with both vildagliptin $(-1.0 \%)$ and metformin $(-1.4 \%)$, although vildagliptin was not noninferior to metformin. ${ }^{32}$ Twice as many patients experienced gastrointestinal adverse events in the metformin group, driven by a 3-4-fold greater incidence of diarrhea, nausea, and abdominal pain. Efficacy was equally well sustained with both treatments over 2 years in the extension study, with a mean $\mathrm{HbA}_{1 \mathrm{c}}$ reduction of $-1.0 \%$ with vildagliptin from a baseline of $8.4 \%$ and a continued benefit in terms of gastrointestinal tolerability. ${ }^{27,32}$

Clinically relevant efficacy of vildagliptin was also seen in a 24-week study comparing vildagliptin ( $50 \mathrm{mg}$ twice daily, $\mathrm{n}=519$ ) and rosiglitazone ( $8 \mathrm{mg}$ daily, $\mathrm{n}=267$ ). Both drugs decreased $\mathrm{HbA}_{1 \mathrm{c}}$ to a similar extent over 24 weeks (statistical noninferiority established), with improvements in $\mathrm{HbA}_{1 \mathrm{c}}$ of $-1.1 \%$ with vildagliptin and $-1.3 \%$ with rosiglitazone from a baseline of $8.7 \%$, and showing some weight benefit with vildaglitpin (-1.9 $\mathrm{kg}$ relative to rosiglitazone) ${ }^{29}$

In a study conducted with vildagliptin $50 \mathrm{mg}$ twice daily versus a sulfonylurea (gliclazide up to $320 \mathrm{mg} /$ day) over a 2-year period, the reductions in $\mathrm{HbA}_{1 \mathrm{c}}$ were similar with both drugs ( $-0.5 \%$ and $-0.6 \%$, respectively), although noninferiority to gliclazide was narrowly not established, and vildagliptin had modest benefits in terms of weight and hypoglycemia. ${ }^{26}$ It is important to point out that with the high baseline $\mathrm{HbA}_{1 \mathrm{c}}$ seen in this study $(8.7 \%$ in the gliclazide group and $8.5 \%$ in the vildagliptin group), any benefit on hypoglycemia and weight versus a sulfonylurea would be expected to be limited, while these benefits would be considerably more pronounced with a lower baseline $\mathrm{HbA}_{1 \mathrm{c}}$ level, as was indeed demonstrated in a study comparing vildagliptin with sulfonylurea as an add on to metformin therapy. 4,35 
Table I Vildagliptin monotherapy studies

\begin{tabular}{|c|c|c|c|c|}
\hline Study & Study description & Randomized patients* & Treatment duration** & Reference \\
\hline $\mathrm{I}$ & $\begin{array}{l}\text { Placebo-controlled dose-ranging study } \\
\text { (efficacy/safety) in drug-naïv T2DM } \\
\text { patients }\left(\mathrm{HbA}_{\mathrm{Ic}} 7.5 \%-10.0 \%\right)\end{array}$ & 354 & 24 weeks & 34 \\
\hline 2 & $\begin{array}{l}\text { Placebo-controlled dose-ranging study } \\
\text { (efficacy/safety) in drug-naïv T2DM } \\
\text { patients }\left(\mathrm{HbA}_{\mathrm{Ic}} 7.5 \%-10.0 \%\right)\end{array}$ & 632 & 24 weeks & 25 \\
\hline 3 & $\begin{array}{l}\text { Placebo-controlled long-term efficacy/safety study in } \\
\text { drug-naïv T2DM patients with mild hyperglycemia } \\
\left(\mathrm{HbA}_{\mathrm{Ic}} 6.2 \%-7.5 \%\right)\end{array}$ & 306 & 52 weeks & 31 \\
\hline 4 & Placebo-controlled 52-week extension to study 3 & 131 & 104 weeks & 30 \\
\hline 5 & $\begin{array}{l}\text { Placebo-controlled mechanistic study in } \\
\text { drug-naïv T2DM patients with mild } \\
\text { hyperglycemia }\left(\mathrm{HbA}_{\mathrm{Ic}} \leq 7.5 \%\right)\end{array}$ & 89 & 52 weeks & 36 \\
\hline 6 & $\begin{array}{l}\text { Placebo-controlled efficacy/mechanistic } \\
\text { study in diet-controlled T2DM patients } \\
\left(\mathrm{HbA}_{\mathrm{lc}} 6.3 \%-10.0 \%\right)\end{array}$ & 40 & 4 weeks & 38 \\
\hline 7 & $\begin{array}{l}\text { Placebo-controlled mechanistic study in } \\
\text { drug-naïve T2DM patients }\left(\mathrm{HbA}_{1 \mathrm{c}} 6.5 \%-10.0 \%\right)\end{array}$ & 31 & 4 weeks & 39 \\
\hline 8 & $\begin{array}{l}\text { Placebo-controlled mechanistic study in } \\
\text { drug-naïve T2DM patients }\left(\mathrm{HbA}_{\mathrm{Ic}} \leq 7.5 \%\right)\end{array}$ & 30 & 4 weeks & 40 \\
\hline 9 & $\begin{array}{l}\text { Active-controlled (metformin) long-term } \\
\text { efficacy/safety study in drug-naive } \\
\text { T2DM patients }\left(\mathrm{HbA}_{\mathrm{Ic}} 7.5 \%-11.0 \%\right)\end{array}$ & 780 & 52 weeks & 32 \\
\hline 10 & $\begin{array}{l}\text { Active-controlled (metformin) 52-week } \\
\text { extension to study } 9\end{array}$ & 463 & 104 weeks & 27 \\
\hline 11 & $\begin{array}{l}\text { Active-controlled (metformin) efficacy/safety study } \\
\text { in drug-naïve elderly ( } \geq 65 \text { years) T2DM patients } \\
\left(\mathrm{HbA}_{\mathrm{Ic}} 7.0 \%-9.0 \%\right)\end{array}$ & 335 & 24 weeks & 33 \\
\hline 12 & $\begin{array}{l}\text { Active-controlled (gliclazide) long-term efficacy/safety } \\
\text { study in drug-naïve } T 2 \mathrm{DM} \text { patients }\left(\mathrm{HbA}_{1 \mathrm{c}} 7.5 \%-11 \%\right)\end{array}$ & 1092 & 104 weeks & 26 \\
\hline 13 & $\begin{array}{l}\text { Active-controlled (acarbose) efficacy/safety study in } \\
\text { drug-naive T2DM patients }\left(\mathrm{HbA}_{1 \mathrm{c}} 7.5 \%-11 \%\right)\end{array}$ & 661 & 24 weeks & 28 \\
\hline 14 & $\begin{array}{l}\text { Active-controlled (rosiglitazone) efficacy/safety study } \\
\left.\text { in drug-naïve T2DM patients ( } \mathrm{HbA}_{\mathrm{Ic}} 7.5 \%-11 \%\right)\end{array}$ & 786 & 24 weeks & 29 \\
\hline 15 & $\begin{array}{l}\text { Active-controlled (voglibose) efficacy/safety study in } \\
\text { Japanese T2DM patients }\left(\mathrm{HbA}_{\mathrm{Ic}} 6.5 \%-10 \%\right)\end{array}$ & 380 & 12 weeks & 37 \\
\hline 16 & Placebo-controlled study in subjects with IGT & 179 & 12 weeks & 49 \\
\hline 17 & Uncontrolled study in subjects with IFG & 22 & 6 weeks & 50 \\
\hline 18 & $\begin{array}{l}\text { Pooled monotherapy analysis in patients } \\
<\text { and } \geq 65 \text { years }\end{array}$ & NA & $\geq 24$ weeks & 10 \\
\hline 19 & $\begin{array}{l}\text { Pooled monotherapy analysis in patients } \\
<\text { and } \geq 75 \text { years }\end{array}$ & NA & $\geq 24$ weeks & 45 \\
\hline
\end{tabular}

Notes: *For extension studies, patients who entered extension; **For extension studies, duration of core + extension study.

Abbreviations: $\mathrm{HbA}_{\mathrm{Ic}}$, glycosylated hemoglobin; IGT, impaired glucose tolerance; IFG, impaired fasting glucose; NA, not applicable; T2DM, type 2 diabetes.

The efficacy of vildagliptin monotherapy was also established in an Asian population. In a 24-week monotherapy study, vildagliptin $50 \mathrm{mg}$ twice daily showed efficacy comparable with that of acarbose administered up to $100 \mathrm{mg}$ three times daily in Chinese patients $(-1.4 \%$ versus $-1.3 \%$ from a baseline of $8.6 \%$; statistical noninferiority established) and was associated with significantly better gastrointestinal tolerability than was the alpha-glucosidase inhibitor. ${ }^{28}$

In a placebo-controlled 24-week study, $\mathrm{HbA}_{1 \mathrm{c}}$ was significantly reduced versus placebo by $-0.48 \%,-0.73 \%$, and $-0.85 \%$ with vildagliptin $50 \mathrm{mg}$ once daily, $50 \mathrm{mg}$ twice daily, and $100 \mathrm{mg}$ once daily, respectively, from baselines of $8.3 \%-8.4 \%$, with no weight gain and no hypoglycemia. ${ }^{25,34}$ Statistically significant reductions versus placebo were also seen with vildagliptin in a second study of identical design, although in this study similar reductions in $\mathrm{HbA}_{1 \mathrm{c}}$ were seen with $50 \mathrm{mg}$ and $100 \mathrm{mg}$ daily, ${ }^{25,34}$ as discussed further below.

In trying to define how vildagliptin might be used most effectively in monotherapy, the first patient segment of interest is patients with relatively mild hyperglycemia. As 
outlined above, for patients in whom the dose or use of metformin is limited (mostly because of gastrointestinal and glomerular filtration rate limitations), using a sulfonylurea as alternative monotherapy treatment is less desirable in patients at low baseline $\mathrm{HbA}_{1 \mathrm{c}}$ because of the increased likelihood of hypoglycemia, ${ }^{23}$ which creates a greater need for other drug choices in this patient group.

The benefit of vildagliptin monotherapy in patients with mild hyperglycemia was evaluated in a series of studies that showed the positive effects of treatment with vildagliptin on glucose control and $\beta$-cell function in this patient population. ${ }^{30,31,36}$

In a one-year, placebo-controlled study involving 306 drug-naive T2DM patients with a mean $\mathrm{HbA}_{1 \mathrm{c}}$ of $6.7 \%$, those randomized to vildagliptin $50 \mathrm{mg}$ once daily plus lifestyle counseling showed a significant reduction in $\mathrm{HbA}_{1 \mathrm{c}}(-0.3 \%)$, fasting plasma glucose $(-0.4 \mathrm{mmol} / \mathrm{L})$, and postprandial glucose $(-0.9 \mathrm{mmol} / \mathrm{L})$ after 52 weeks, relative to those receiving placebo plus lifestyle counseling (Figure 1). ${ }^{31}$ A one-year extension was conducted (total study duration 2 years) and showed continued improvement with vildagliptin relative to placebo, with a placebo-adjusted change in $\mathrm{HbA}_{1 \mathrm{c}}$ of $-0.5 \%$ from core study baseline after 2 years. Body weight decreased significantly in vildagliptin-treated patients $(-1.1 \mathrm{~kg}$ versus $-0.3 \mathrm{~kg}$ with placebo), and two placebo-treated patients $(3.2 \%)$ versus none $(0.0 \%)$ receiving vildagliptin experienced hypoglycemia over 2 years. Taken together, 104 weeks of treatment with vildagliptin in this study mitigated the progressive loss of glycemic control observed in patients with mild hyperglycemia receiving placebo and lifestyle counseling without exposing them to hypoglycemia or weight gain. ${ }^{30}$ This appears to be because of a corresponding attenuation of the deterioration of $\beta$-cell function as assessed by the insulin secretion rate relative to glucose over one and 2 years. ${ }^{30} \beta$-cell function also showed significant improvement with vildagliptin $100 \mathrm{mg}$ once daily in a subsequent study in the same patient population, which demonstrated that vildagliptin significantly increased the insulin secretory capacity of $\beta$-cells, using the current gold standard clamp assessment of $\beta$-cell secretory capacity. ${ }^{36}$

Another monotherapy study (24 weeks) with vildagliptin in a low baseline population (mean $\mathrm{HbA}_{1 \mathrm{c}} 7.7 \%$ ) was conducted versus metformin $1.5 \mathrm{~g}$ daily in patients aged 65 years and older. This study showed that vildagliptin $100 \mathrm{mg}$ once daily was as effective as metformin in this population, improving $\mathrm{HbA}_{1 \mathrm{c}}$ by $-0.64 \%$ and $-0.75 \%$, respectively (noninferiority established), with fewer gastrointestinal adverse events with vildagliptin (15.0\% versus $24.8 \%$ with

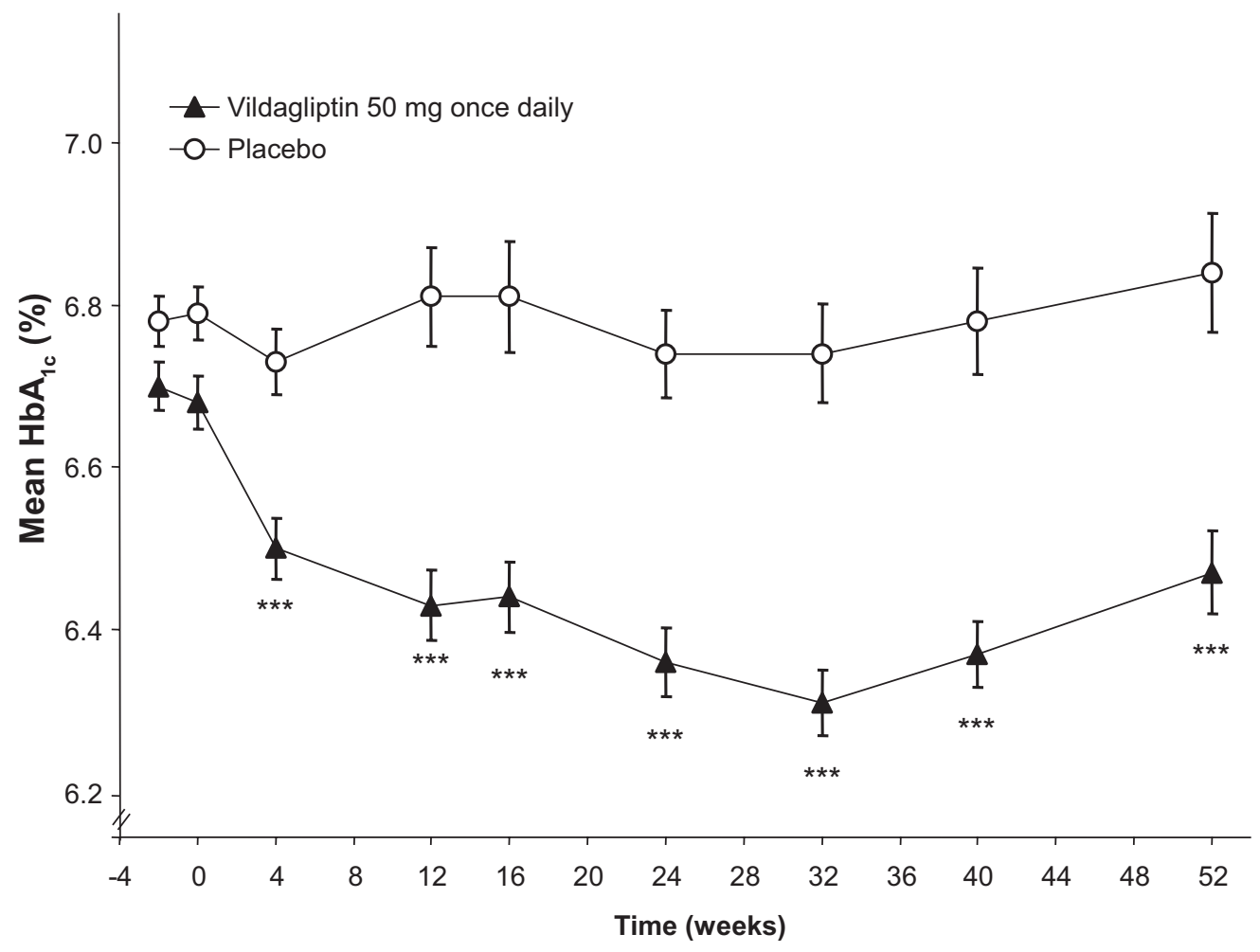

Figure I Time course of mean $\mathrm{HbA}_{\mathrm{lc}}$ during one year of treatment with vildagliptin $50 \mathrm{mg}$ once daily (closed triangles) or placebo (open circles).

Notes: Vildagliptin: $\mathrm{n}=153$ at baseline and I 38 at week 52; placebo: $\mathrm{n}=\mid 49$ at baseline and I3I at week 52 . Mean \pm standard error. $* * * P<0.000 \mid$ versus placebo. Adapted with permission from Scherbaum et al. ${ }^{31}$ 
metformin, $P=0.028$ ), mainly driven by a 4.4 -fold higher incidence of diarrhea with metformin. ${ }^{33}$

The efficacy of vildagliptin monotherapy in patients with low baseline $\mathrm{HbA}_{1 \mathrm{c}}$ was also evaluated in an Asian population. In a 12-week study in Japanese patients, vildagliptin reduced $\mathrm{HbA}_{1 \mathrm{c}}$ by $-0.95 \%$ from a baseline of $7.9 \%$ (adjusted from a reported Japan Diabetes Society value of 7.5\%). The observed efficacy was superior to that of the alpha-glucosidase inhibitor, voglibose $(-0.38 \% ; P<0.001)$, and was also associated with significantly better gastrointestinal tolerability. ${ }^{37}$

Three additional short-term studies have provided further evidence of the efficacy of vildagliptin in patients with mild hyperglycemia. The first 4-week study showed significant improvements in glycemic control with vildagliptin $100 \mathrm{mg}$ once daily $\left(-0.4 \%\right.$ placebo-subtracted reduction in $\mathrm{HbA}_{1 \mathrm{c}}$; $P<0.001)$ in patients with diet-controlled diabetes and a mean baseline $\mathrm{HbA}_{1 \mathrm{c}}$ of $7.2 \%{ }^{38}$ A second 4-week study reported a significant decrease in $\mathrm{HbA}_{1 \mathrm{c}}$ of $-0.4 \%$ relative to placebo from a baseline of $6.7 \%$ with vildagliptin $50 \mathrm{mg}$ twice daily. ${ }^{39}$ In the third study, ${ }^{40} 4$ weeks of treatment with vildagliptin $100 \mathrm{mg}$ once daily also improved glycemic control, despite a very low baseline $\mathrm{HbA}_{1 \mathrm{c}}$ of approximately $6.3 \%$, with a placebo-adjusted change in $\mathrm{HbA}_{1 \mathrm{c}}$ of $-0.3 \%(P=0.002$ versus placebo). As in previous trials, vildagliptin increased plasma levels of intact glucagon-like peptide-1, reduced prandial glucose and glucagon, and increased insulin secretion relative to glucose, all these changes being independent of the patient's severity of disease or treatment duration.

In addition to the individual studies specifically conducted in the patients with the lower baseline $\mathrm{HbA}_{1 \mathrm{c}}$, the efficacy of vildagliptin in this population was also established in predefined subgroup analyses of studies performed in a broad range of T2DM. In the pivotal study with vildagliptin and metformin monotherapy mentioned earlier, ${ }^{32}$ in the subgroup of patients with baseline $\mathrm{HbA}_{1 \mathrm{c}} \leq 8.0 \%$, mean $\mathrm{HbA}_{1 \mathrm{c}}$ was reduced with vildagliptin $50 \mathrm{mg}$ twice daily by $-0.6 \%$ $(\mathrm{n}=180)$ and by $-0.7 \%$ with metformin $(\mathrm{n}=79)$ from a baseline of approximately $7.6 \%$. Similarly, in the group of patients with baseline $\mathrm{HbA}_{1 \mathrm{c}} \leq 8.0 \%$ in the 24-week study cited above versus rosiglitazone, a reduction of $-0.6 \%$ was seen from a baseline of $7.7 \%$ (unpublished data). Finally, in a placebo-controlled dose-ranging study ${ }^{34}$ in the same predefined subgroup, the placebo-subtracted change in $\mathrm{HbA}_{1 \mathrm{c}}$ with vildagliptin $50 \mathrm{mg}$ twice daily was $-0.7 \%$ from a baseline of $7.7 \%$.

An additional interesting aspect of this latter study was with respect to findings for the dose response to vildagliptin in relation to baseline $\mathrm{HbA}_{1 \mathrm{c}}$. In the subgroup of patients with $\mathrm{HbA}_{1 \mathrm{c}} \leq 8.0 \%$, the placebo-subtracted changes in $\mathrm{HbA}_{1 \mathrm{c}}$ were $-0.8 \%,-0.7 \%$, and $-0.9 \%$ with vildagliptin $50 \mathrm{mg}$ once daily, $50 \mathrm{mg}$ twice daily, and $100 \mathrm{mg}$ once daily, respectively. ${ }^{34}$ Thus, in the lower baseline $\mathrm{HbA}_{1 \mathrm{c}}$ subgroup $(\mathrm{n}=141$; mean baseline approximately $7.6 \%$ ), the effect of vildagliptin was not dose-related. In contrast, in patients with baseline $\mathrm{HbA}_{1 \mathrm{c}}>8.0 \%(\mathrm{n}=199$; mean baseline 8.9\%), 2-fold greater $\mathrm{HbA}_{1 \mathrm{c}}$ reductions from baseline were observed with the $50 \mathrm{mg}$ twice daily and $100 \mathrm{mg}$ once daily doses versus the $50 \mathrm{mg}$ once-daily dose regimen. ${ }^{34}$ Similar dose-response findings were seen in a second dose-ranging study of similar design. ${ }^{25}$ In the cohort of patients with baseline $\mathrm{HbA}_{1 \mathrm{c}}>8.0 \%$ (8.8\%-9.0\%), greater efficacy was observed with vildagliptin $50 \mathrm{mg}$ twice daily $(-1.3 \%)$ or $100 \mathrm{mg}$ once daily $(-1.4 \%)$ than with the $50 \mathrm{mg}$ once daily dose $(-0.8 \%)$. In contrast, no dose response was seen in the $\leq 8.0 \%$ subgroup. ${ }^{25}$ Taken together, the data from both these studies suggest that, at lower glycemic levels, a benefit of the higher daily dose regimen is not discernible, while at higher levels of glycemia, a $100 \mathrm{mg}$ daily regimen appears to be more effective than the $50 \mathrm{mg}$ daily regimen. This, together with the underlying mechanism, will be further discussed below.

\section{Elderly patients}

The management of T2DM in the elderly is a challenge for clinicians. The elderly are a very heterogeneous population, in whom treatment must be individualized. ${ }^{24}$ Although treatment options overall are similar to those available for younger patients (with metformin remaining the first choice and sulfonylureas still widely used), the avoidance of hypoglycemia is of utmost importance in this population, because the risk of hypoglycemia is higher and the consequences more dramatic in older patients. ${ }^{41}$ In addition, the elderly are more likely to have multiple cardiovascular risk factors and higher rates of medical comorbidities, including undiagnosed renal impairment and depression, as well as an increased risk of drug-drug interactions from polypharmacy. All of these considerations can limit the therapeutic choices and may reduce the degree of aggressiveness with which clinicians may attempt to reach and sustain the goals of treatment. ${ }^{41}$ However, while many older individuals with diabetes are on multiple antidiabetic therapies (with or without insulin) because of advanced disease, about $20 \%$ of the elderly are recently diagnosed ${ }^{42}$ and thus still represent an appropriate population for monotherapy.

There are considerable data on the use of vildagliptin in elderly patients who are still good candidates for monotherapy and for whom insulin is neither clinically necessary nor practical. ${ }^{9}$ 
In the 24-week head-to-head study versus metformin briefly mentioned earlier, ${ }^{33}$ which was conducted in T2DM patients with a mean age of 71 years and a mean duration of T2DM since diagnosis of 3 years, vildagliptin $100 \mathrm{mg}$ once daily was as effective as metformin $1.5 \mathrm{~g} /$ day, a dose adapted to this older population, in reducing $\mathrm{HbA}_{1 \mathrm{c}}$. Adverse event rates were numerically lower with vildagliptin than with metformin (44.3\% versus $50.3 \%$ ) because of the better gastrointestinal tolerability profile of vildagliptin, and a low rate of hypoglycemia was observed in both groups. ${ }^{33}$ It is also worth mentioning that in the 2-year study discussed earlier in patients with a mean $\mathrm{HbA}_{1 \mathrm{c}}$ of $6.8 \%,{ }^{30}$ half of the population was older than 65 years.

Vildagliptin monotherapy was also shown to be effective and well tolerated in treatment-naive elderly patients in a pooled analysis of five monotherapy trials comparing the effects of 24 weeks of vildagliptin treatment in younger ( $<65$ years, $n=1231)$ and older ( $\geq 65$ years, $n=238$ ) patients. ${ }^{10}$ Despite having lower mean baseline $\mathrm{HbA}_{1 \mathrm{c}}$ and fasting plasma glucose, older patients had at least as good reductions in both measures relative to younger individuals $(-1.2 \%$ versus $-1.0 \%[P=0.092]$ and $-1.5 \mathrm{mmol} / \mathrm{L}$ versus $-1.1 \mathrm{mmol} / \mathrm{L}[P=0.035]$, respectively). The rate of hypoglycemia was low $(0.8 \%)$. Although adverse event rates were slightly higher in older patients compared with the younger population, older patients taking vildagliptin had lower adverse event rates $(63.6 \%)$ than did older patients taking active comparators (68.1\%). Worth noting, too, is the finding that vildagliptin did not increase the incidence of adverse events in patients with mild renal impairment (62\%) relative to normal individuals. ${ }^{10}$

While this pooled analysis only included patients with mild renal impairment (estimated glomerular filtration rate $60-90 \mathrm{~mL} /$ minute $/ 1.73 \mathrm{~m}^{2}$ ), the safety and efficacy of vildagliptin $50 \mathrm{mg}$ once daily has recently been established in patients with moderate (estimated glomerular filtration rate $30-60 \mathrm{~mL} / \mathrm{minute} / 1.73 \mathrm{~m}^{2}$ ) and severe (estimated glomerular filtration rate $<30 \mathrm{~mL} /$ minute $/ 1.73 \mathrm{~m}^{2}$ ) renal impairment in a large study, which included 515 patients, ${ }^{43}$ and is now indicated in these populations. When considering treating elderly patients, it is indeed important to know that vildagliptin can be used safely and effectively independent of renal function. Renal impairment is a key limitation with the use of many oral antidiabetic drugs and is quite common, though sometimes undetected, in T2DM patients. Recent data from a retrospective database analysis using General Electric medical records found that $35 \%$ of T2DM patients had evidence of moderate to severe renal impairment, often unrecognized. ${ }^{44}$ In the recent French ENTRED cohort of patients aged 65 years and older, this was the case for $28 \%$ of patients, with renal function status unknown in $13 \%$ of the population. ${ }^{42}$

The utility/effectiveness of vildagliptin monotherapy in elderly T2DM patients was further confirmed in a population aged $\geq 75$ years in a second pooled analysis (Figure 2). ${ }^{45}$ In the monotherapy group, $\mathrm{HbA}_{1 \mathrm{c}}$ decreased by $-0.9 \%$, ie, from a baseline of $8.3 \%$ to $7.4 \%$ at week $24(P<0.0001)$, a reduction similar to that reported in younger patients. There were no confirmed hypoglycemic events, and adverse events, drug-related adverse events, serious adverse events, and deaths were all reported at a lower frequency among patients receiving vildagliptin relative to comparators.

In summary, vildagliptin monotherapy could be a credible alternative for elderly T2DM patients who cannot use metformin, offering similar efficacy while not being limited by gastrointestinal tolerability or by renal impairment, which is frequent in this population. Vildagliptin monotherapy provided clinically meaningful improvement in glycemic
A

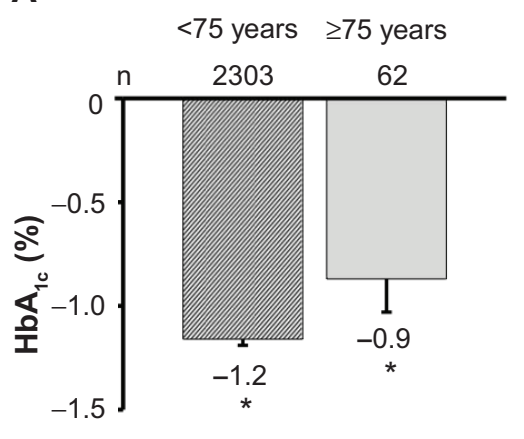

B

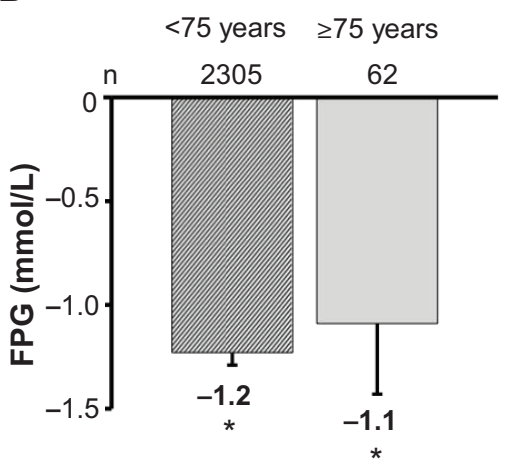

C

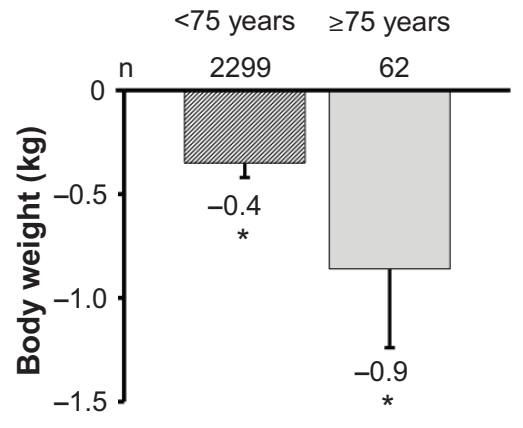

Figure 2 Change from baseline in $\mathrm{HbA}_{\mathrm{lc}}(\mathbf{A})$, fasting plasma glucose $(\mathbf{B})$, and weight $(\mathbf{C})$ with vildagliptin 50 mg twice daily in a pooled monotherapy population in patients stratified by age. ${ }^{45} * \mathrm{P}<0.05$ versus baseline; baseline values for patients $<75$ years and $\geq 75$ years were $8.7 \%$ and $8.3 \%$, respectively $(\mathbf{A})$; $10.5 \mathrm{mmol} / \mathrm{L}$ and $9.7 \mathrm{mmol} / \mathrm{L}(\mathbf{B})$; and $86.1 \mathrm{~kg}$ and $74.9 \mathrm{~kg}(\mathbf{C})$. 
control, that was associated with an acceptably low rate of side effects and little risk of hypoglycemia.

\section{Patients with prediabetes}

Prediabetic conditions include impaired glucose tolerance, impaired fasting glucose, or both. Individuals with prediabetes are at high risk for development of T2DM, with 50\% progressing to T2DM over their lifetime. ${ }^{46,47}$ Defects in insulin action and $\beta$-cell function are characteristic of both impaired glucose tolerance and impaired fasting glucose, and progressive $\beta$-cell failure is the primary abnormality responsible for conversion of impaired glucose tolerance/impaired fasting glucose to overt diabetes. While lifestyle modification is the currently accepted treatment option for prediabetic individuals, these patients might one day be candidates for drug treatment, should treatment paradigms evolve to include individuals at the earliest disease stages. The release of 10-year follow-up data from the United Kingdom Prospective Diabetes Study ${ }^{48}$ showed a clear legacy effect, with intensive glucose control introduced at the time of diagnosis being associated with a significantly reduced risk of myocardial infarction, all-cause mortality, and microvascular disease. ${ }^{48}$ These findings offer substantial support for a benefit of optimal glycemic control as early as possible in the disease process. Other than metformin, vildagliptin, given its mechanism of action, could potentially be an attractive future treatment option for these patients, should treatment guidelines move towards earlier drug treatment. In this context, it is of interest to review the data that have been collected on the use of vildagliptin in two small studies of patients with impaired glucose tolerance and with impaired fasting glucose.

A 12-week placebo-controlled study examined the effects of vildagliptin monotherapy (50 mg once daily) in individuals with impaired glucose tolerance $(n=179) .{ }^{49}$ The results demonstrated that the mechanisms supporting the efficacy of vildagliptin in T2DM patients are operative in prediabetes as well. Relative to placebo, there was a marked increase in the postprandial GLP-1 and GIP responses with vildagliptin, which was associated with improvement in both $\beta$-cell function (increased insulin secretion relative to glucose) and $\alpha$-cell function (reduction of inappropriate glucagon release following a high carbohydrate meal), leading to decreased postprandial glucose levels. Twelve weeks of treatment with vildagliptin also led to a small but significant reduction in $\mathrm{HbA}_{1 \mathrm{c}}$ from normal baseline levels, and patients did not experience any weight gain. ${ }^{49}$

In a small, uncontrolled, 6-week study in patients with impaired fasting glucose $(\mathrm{n}=22),{ }^{50}$ vildagliptin $100 \mathrm{mg}$ once daily was also shown to increase postprandial levels of intact GLP-1 and GIP, to increase insulin and C-peptide responses to intravenous glucose, and to enhance insulin sensitivity, while reducing glycemia.

Taken together, these two studies provide evidence that the known effects of vildagliptin on incretin levels and islet function in T2DM can be reproduced in subjects with impaired glucose tolerance and impaired fasting glucose.

\section{Therapeutic considerations}

Although different doses have been studied throughout the vildagliptin development program, as is also apparent from the current review of the different monotherapy studies, the two marketed doses of vildagliptin are $50 \mathrm{mg}$ once daily and $50 \mathrm{mg}$ twice daily. In monotherapy, vildagliptin is approved in some countries as $50 \mathrm{mg}$ twice daily only (eg, Japan and the European Union) and in other countries as both $50 \mathrm{mg}$ once daily and $50 \mathrm{mg}$ twice daily (eg, Switzerland and countries that refer to Switzerland for drug approval). These differences in approved dosing regimens represent different regulatory philosophies. From a risk point of view, no additional risk has been associated with the $50 \mathrm{mg}$ twice-daily dose as opposed to the $50 \mathrm{mg}$ once-daily dose and overall maximum efficacy is achieved at the twice-daily dose. ${ }^{25,34}$ On the other hand, it is clear from the dose-ranging studies that some patients do not see additional benefit of the $50 \mathrm{mg}$ twice-daily dose compared with the $50 \mathrm{mg}$ once-daily dose, and thus some countries label the choice of either dosage frequency. It is useful to examine the basis for this choice and how it might be applied in practice.

Vildagliptin $50 \mathrm{mg}$ once daily blocks DPP-4 activity over the course of the three daily meals, which reduces postprandial glucose during these meals. Vildagliptin $50 \mathrm{mg}$ twice daily blocks DDP-4 activity over 24 hours, resulting in direct inhibition of overnight hepatic glucose production, which plays a more prominent role as the disease progresses. ${ }^{51}$

Most often the progression of T2DM starts with impaired glucose tolerance (ie, elevated postprandial glucose), and fasting plasma glucose can also rise secondary to the elevated postprandial glucose levels because of increased Cori cycling. ${ }^{52}$ With further progression of the disease, this is usually followed by much larger increases of fasting plasma glucose due to increasing levels of overnight hepatic glucose production. On average, in patients with baseline $\mathrm{HbA}_{1 \mathrm{c}}$ levels $\leq 8 \%$, much of the glycemic exposure is driven by elevated postprandial glucose, whereas in patients with baseline 
$\mathrm{HbA}_{1 \mathrm{c}}$ levels $>8 \%$, most of the glycemic exposure is driven by elevated fasting plasma glucose. ${ }^{53}$ However, while this is generally true in populations, in individuals an $\mathrm{HbA}_{1 \mathrm{c}}$ of $7 \%-8 \%$ may still be associated with a fasting plasma glucose of $7 \mathrm{mM}$, which is not associated with an important rise in overnight hepatic glucose production, or with a fasting plasma glucose of up to $10 \mathrm{mM}$, which is associated with an important rise in overnight hepatic glucose production. ${ }^{51}$ In addition, in a clinical setting, fasting plasma glucose is quite variable. These considerations make it difficult to determine which individual patients experience glycemia that is not primarily driven by overnight hepatic glucose production.

Thus, while in patients with a baseline $\mathrm{HbA}_{1 \mathrm{c}} \leq 8.0 \%$ in study populations there was on average no efficacy benefit associated with the twice-daily versus once-daily vildagliptin dose, as discussed earlier, using either $\mathrm{HbA}_{1 \mathrm{c}}$ or fasting plasma glucose as a basis for using a once-daily dose in individuals may result in some patients receiving a suboptimal dose. In the absence of any safety or tolerability issues associated with the twice-daily dose versus the once-daily dose, the European and Japanese labels recommend twicedaily dosing for vildagliptin monotherapy in all patients.

It is worth mentioning the following further consideration related to dosing. In addition to the pancreatic effect of reducing glycemia, vildagliptin has an extrapancreatic effect of reducing fasting lipolysis treatment. ${ }^{54}$ Over weeks, reduced fasting lipolysis leads to reduced levels of stored triglycerides in nonfat tissues (muscle and liver), as shown by increased insulin-mediated glucose disposal at the expense of lipid oxidation (ie, reduced lipotoxicity) observed after 6 weeks of vildagliptin $50 \mathrm{mg}$ twice daily treatment. ${ }^{54}$ Because fasting lipolysis occurs during the overnight postabsorptive period, this effect requires twice-daily dosing to cover the overnight period. The additional benefit of reduced lipotoxicity with vildagliptin may be an important contributor to an improved metabolic state.

Taken together, in most patients with normal or mildly impaired renal function, vildagliptin $50 \mathrm{mg}$ twice daily is the appropriate dose for monotherapy. Of note, in patients with moderate or severe renal impairment, vildagliptin $50 \mathrm{mg}$ once daily blocks DPP-4 activity over 24 hours (reflecting the increased exposure) and thus $50 \mathrm{mg}$ once daily is the appropriate dose. ${ }^{43}$

\section{Conclusion}

Vildagliptin has been shown to be a well tolerated and efficacious monotherapy for patients with T2DM. The ability of vildagliptin to improve glucose tolerance also extends into the impaired glucose tolerance and impaired fasting glucose populations. When metformin is not appropriate, vildagliptin has hypoglycemic and weight benefits relative to sulfonylureas, particularly appreciable in patients with lower baseline $\mathrm{HbA}_{1 \mathrm{c}}$ levels and in the elderly population.

\section{Disclosure}

The authors are employees of Novartis.

\section{References}

1. Ahren B, Foley JE. The islet enhancer vildagliptin: mechanisms of improved glucose metabolism. Int J Clin Pract Suppl. 2008;159: $8-14$.

2. Keating GM. Vildagliptin: a review of its use in type 2 diabetes mellitus. Drugs. 2010;70:2089-2112.

3. Fonseca V, Baron M, Shao Q, Dejager S. Sustained efficacy and reduced hypoglycemia during one year of treatment with vildagliptin added to insulin in patients with type 2 diabetes mellitus. Horm Metab Res. 2008;40:427-430.

4. Matthews DR, Dejager S, Ahren B, et al. Vildagliptin add-on to metformin produces similar efficacy and reduced hypoglycaemic risk compared with glimepiride, with no weight gain: results from a 2-year study. Diabetes Obes Metab. 2010;12:780-789.

5. Ahren B, Foley JE, Bosi E. Clinical evidence and mechanistic basis for vildagliptin's action when added to metformin. Diabetes Obes Metab. 2011;13:193-203.

6. Schweizer A, Dejager S, Foley JE, Kothny W. Assessing the general safety and tolerability of vildagliptin: value of pooled analyses from a large safety database versus evaluation of individual studies. Vasc Health Risk Manag. 2011;7:49-57.

7. Schweizer A, Dejager S, Foley JE, Couturier A, Ligueros-Saylan M, Kothny W. Assessing the cardio-cerebrovascular safety of vildagliptin: meta-analysis of adjudicated events from a large Phase III type 2 diabetes population. Diabetes Obes Metab. 2010;12:485-494.

8. Ligueros-Saylan M, Foley JE, Schweizer A, Couturier A, Kothny W. An assessment of adverse effects of vildagliptin versus comparators on the liver, the pancreas, the immune system, the skin and in patients with impaired renal function from a large pooled database of Phase II and III clinical trials. Diabetes Obes Metab. 2010;12: 495-509.

9. Halimi S, Raccah D, Schweizer A, Dejager S. Role of vildagliptin in managing type 2 diabetes mellitus in the elderly. Curr Med Res Opin. 2010;26:1647-1656.

10. Pratley RE, Rosenstock J, Pi-Sunyer FX, et al. Management of type 2 diabetes in treatment-naive elderly patients: benefits and risks of vildagliptin monotherapy. Diabetes Care. 2007;30: 3017-3022.

11. Ahren B, Schweizer A, Dejager S, Villhauer EB, Dunning BE, Foley JE. Mechanisms of action of the dipeptidyl peptidase- 4 inhibitor vildagliptin in humans. Diabetes Obes Metab. 2011;13:775-783.

12. Foley JE, Jordan J. Weight neutrality with the DPP-4 inhibitor, vildagliptin: mechanistic basis and clinical experience. Vasc Health Risk Manag. 2010;6:541-548.

13. Dejager S, Schweizer A. Minimizing the risk of hypoglycemia with vildagliptin: Clinical experience, mechanistic basis, and importance in type 2 diabetes management. Diabetes Ther. 2011;2:51-66.

14. Cai L, Cai Y, Lu ZJ, Zhang Y, Liu P. The efficacy and safety of vildagliptin in patients with type 2 diabetes: a meta-analysis of randomized clinical trials. J Clin Pharm Ther. December 22, 2011. [Epub ahead of print.] 
15. Halimi S. Metformin: 50 years old, fit as a fiddle, and indispensable for its pivotal role in type 2 diabetes management. Diabetes Metab. 2006;32:555-556.

16. Bouchoucha M, Uzzan B, Cohen R. Metformin and digestive disorders. Diabetes Metab. 2011;37:90-96.

17. Nichols GA, Conner C, Brown JB. Initial nonadherence, primary failure and therapeutic success of metformin monotherapy in clinical practice. Curr Med Res Opin. 2010;26:2127-2135.

18. Li C, Hung YJ, Qamruddin K, Aziz MF, Stein H, Schmidt B. International noninterventional study of acarbose treatment in patients with type 2 diabetes mellitus. Diabetes Res Clin Pract. 2011;92: 57-64.

19. Aubert RE, Herrera V, Chen W, Haffner SM, Pendergrass M. Rosiglitazone and pioglitazone increase fracture risk in women and men with type 2 diabetes. Diabetes Obes Metab. 2010;12: 716-721.

20. Lewis JD, Ferrara A, Peng T, et al. Risk of bladder cancer among diabetic patients treated with pioglitazone: interim report of a longitudinal cohort study. Diabetes Care. 2011;34:916-922.

21. Piccinni C, Motola D, Marchesini G, Poluzzi E. Assessing the association of pioglitazone use and bladder cancer through drug adverse event reporting. Diabetes Care. 2011;34:1369-1371.

22. Barnett AH, Cradock S, Fisher M, Hall G, Hughes E, Middleton A. Key considerations around the risks and consequences of hypoglycaemia in people with type 2 diabetes. Int J Clin Pract. 2010;64:1121-1129.

23. Cryer PE. The barrier of hypoglycemia in diabetes. Diabetes. 2008; 57:3169-3176.

24. Bourdel-Marchasson I, Schweizer A, Dejager S. Incretin therapies in the management of elderly patients with type 2 diabetes mellitus. Hosp Pract (Minneap). 2011;39:7-21

25. Dejager S, Razac S, Foley JE, Schweizer A. Vildagliptin in drugnaive patients with type 2 diabetes: a 24 -week, double-blind, randomized, placebo-controlled, multiple-dose study. Horm Metab Res. 2007;39:218-223.

26. Foley JE, Sreenan S. Efficacy and safety comparison between the DPP-4 inhibitor vildagliptin and the sulfonylurea gliclazide after two years of monotherapy in drug-naive patients with type 2 diabetes. Horm Metab Res. 2009;41:905-909.

27. Goke B, Hershon K, Kerr D, et al. Efficacy and safety of vildagliptin monotherapy during 2-year treatment of drug-naive patients with type 2 diabetes: comparison with metformin. Horm Metab Res. 2008;40:892-895.

28. Pan C, Yang W, Barona JP, et al. Comparison of vildagliptin and acarbose monotherapy in patients with type 2 diabetes: a 24-week, double-blind, randomized trial. Diabet Med. 2008;25:435-441.

29. Rosenstock J, Baron MA, Dejager S, Mills D, Schweizer A. Comparison of vildagliptin and rosiglitazone monotherapy in patients with type 2 diabetes: a 24-week, double-blind, randomized trial. Diabetes Care. 2007;30:217-223.

30. Scherbaum WA, Schweizer A, Mari A, et al. Evidence that vildagliptin attenuates deterioration of glycaemic control during 2-year treatment of patients with type 2 diabetes and mild hyperglycaemia. Diabetes Obes Metab. 2008;10:1114-1124.

31. Scherbaum WA, Schweizer A, Mari A, et al. Efficacy and tolerability of vildagliptin in drug-naive patients with type 2 diabetes and mild hyperglycaemia. Diabetes Obes Metab. 2008;10:675-682.

32. Schweizer A, Couturier A, Foley JE, Dejager S. Comparison between vildagliptin and metformin to sustain reductions in $\mathrm{HbA}(1 \mathrm{c})$ over 1 year in drug-naive patients with Type 2 diabetes. Diabet Med. 2007;24:955-961.

33. Schweizer A, Dejager S, Bosi E. Comparison of vildagliptin and metformin monotherapy in elderly patients with type 2 diabetes: a 24-week, doubleblind, randomized trial. Diabetes Obes Metab. 2009;11:804-812.

34. Pi-Sunyer FX, Schweizer A, Mills D, Dejager S. Efficacy and tolerability of vildagliptin monotherapy in drug-naive patients with type 2 diabetes. Diabetes Res Clin Pract. 2007;76:132-138.
35. Ferrannini E, Fonseca V, Zinman B, et al. Fifty-two-week efficacy and safety of vildagliptin versus glimepiride in patients with type 2 diabetes mellitus inadequately controlled on metformin monotherapy. Diabetes Obes Metab. 2009;11:157-166.

36. Foley JE, Bunck MC, Moller-Goede DL, et al. Beta cell function following 1 year vildagliptin or placebo treatment and after 12 week washout in drug-naive patients with type 2 diabetes and mild hyperglycaemia: a randomised controlled trial. Diabetologia. 2011;54:1985-1991.

37. Iwamoto Y, Kashiwagi A, Yamada N, et al. Efficacy and safety of vildagliptin and voglibose in Japanese patients with type 2 diabetes: a 12-week, randomized, double-blind, active-controlled study. Diabetes Obes Metab. 2010;12:700-708.

38. Ahren B, Landin-Olsson M, Jansson PA, Svensson M, Holmes D, Schweizer A. Inhibition of dipeptidyl peptidase-4 reduces glycemia, sustains insulin levels, and reduces glucagon levels in type 2 diabetes. J Clin Endocrinol Metab. 2004;89:2078-2084.

39. Matikainen N, Manttari S, Schweizer A, et al. Vildagliptin therapy reduces postprandial intestinal triglyceride-rich lipoprotein particles in patients with type 2 diabetes. Diabetologia. 2006;49: 2049-2057.

40. Ahren B, Schweizer A, Dejager S, et al. Vildagliptin enhances islet responsiveness to both hyper- and hypoglycemia in patients with type 2 diabetes. J Clin Endocrinol Metab. 2009;94:1236-1243.

41. Germino FW. Noninsulin treatment of type 2 diabetes mellitus in geriatric patients: a review. Clin Ther. 2011;33:1868-1882.

42. Pornet C, Bourdel-Marchasson I, Lecomte P, et al. Trends in the quality of care for elderly people with type 2 diabetes: the need for improvements in safety and quality (the 2001 and 2007 ENTRED surveys). Diabetes Metab. 2011;37:152-161.

43. Lukashevich V, Schweizer A, Shao Q, Groop PH, Kothny W. Safety and efficacy of vildagliptin versus placebo in patients with type 2 diabetes and moderate or severe renal impairment: A prospective 24-week randomized placebo-controlled trial. Diabetes Obes Metab. 2011;13:947-954.

44. Meyers JL, Candrilli SD, Kovacs B. Type 2 diabetes mellitus and renal impairment in a large outpatient electronic medical records database: rates of diagnosis and antihyperglycemic medication dose adjustment. Postgrad Med. 2011;123:133-143.

45. Schweizer A, Dejager S, Foley JE, Shao Q, Kothny W. Clinical experience with vildagliptin in the management of type 2 diabetes in a patient population $\geq 75$ years: a pooled analysis from a database of clinical trials. Diabetes Obes Metab. 2011;13:55-64.

46. Gerstein HC, Santaguida P, Raina P, et al. Annual incidence and relative risk of diabetes in people with various categories of dysglycemia: a systematic overview and meta-analysis of prospective studies. Diabetes Res Clin Pract. 2007;78:305-312.

47. Unwin N, Shaw J, Zimmet P, Alberti KG. Impaired glucose tolerance and impaired fasting glycaemia: the current status on definition and intervention. Diabet Med. 2002;19:708-723.

48. Holman RR, Paul SK, Bethel MA, Matthews DR, Neil HA. 10-year follow-up of intensive glucose control in type 2 diabetes. $N$ Engl J Med. 2008;359:1577-1589.

49. Rosenstock J, Foley JE, Rendell M, et al. Effects of the dipeptidyl peptidase-IV inhibitor vildagliptin on incretin hormones, islet function, and postprandial glycemia in subjects with impaired glucose tolerance. Diabetes Care. 2008;31:30-35.

50. Utzschneider KM, Tong J, Montgomery B, et al. The dipeptidyl peptidase-4 inhibitor vildagliptin improves beta-cell function and insulin sensitivity in subjects with impaired fasting glucose. Diabetes Care. 2008;31:108-113.

51. DeFronzo RA, Ferrannini E, Simonson DC. Fasting hyperglycemia in non-insulin-dependent diabetes mellitus: contributions of excessive hepatic glucose production and impaired tissue glucose uptake. Metabolism. 1989;38:387-395. 
52. Yki-Jarvinen H, Bogardus C, Foley JE. Regulation of plasma lactate concentration in resting human subjects. Metabolism. 1990;39: 859-864.

53. Monnier L, Colette C, Dunseath GJ, Owens DR. The loss of postprandial glycemic control precedes stepwise deterioration of fasting with worsening diabetes. Diabetes Care. 2007;30:263-269.
54. Azuma K, Radikova Z, Mancino J, et al. Measurements of islet function and glucose metabolism with the dipeptidyl peptidase 4 inhibitor vildagliptin in patients with type 2 diabetes. J Clin Endocrinol Metab. 2008;93:459-464.

\section{Publish your work in this journal}

Vascular Health and Risk Management is an international, peerreviewed journal of therapeutics and risk management, focusing on concise rapid reporting of clinical studies on the processes involved in the maintenance of vascular health; the monitoring, prevention and treatment of vascular disease and its sequelae; and the involvement of metabolic disorders, particularly diabetes. This journal is indexed on PubMed Central and MedLine. The manuscript management system is completely online and includes a very quick and fair peer-review system, which is all easy to use. Visit http://www.dovepress.com/ testimonials.php to read real quotes from published authors.

Submit your manuscript here: http://www.dovepress.com/vascular-health-and-risk-management-journal 